\title{
Assessing Interaction Styles in Web User Interfaces
}

\author{
Alistair Sutcliffe and Antonella De Angeli \\ Centre for HCI Design, School of Informatics, University of Manchester, \\ P.O. Box 88, Manchester M60 1QD, UK \\ a.g.sutcliffe@co.umist.ac.uk
}

\begin{abstract}
An evaluation of two websites with the same content but different interface styles (traditional menu-based and interactive metaphors) is described. A formative usability evaluation was carried out with heuristic assessment of aesthetics followed by post-test memory. The subjects had more problems with the metaphor-based site, but rated it more favourably on the aesthetics heuristics. There was no difference in free memory recall between the sites. The implications for website design and evaluation are discussed.
\end{abstract}

\section{Introduction}

Conceptions of "new usability" propose that overall satisfaction with user interfaces involves not only traditional usability but also other factors such as user engagement, experience, and aesthetics [5]. Some heuristic evaluation techniques make reference to aesthetics and user engagement [8], [12], [13]. However, few experimental investigations into aesthetic components of usability have been carried out apart from those by Tractinsky [17], who demonstrated that users' perception of aesthetic qualities was an important, and culturally variable, component in the rating of quality in experiments with ATM user interfaces. Further evidence for the importance of aesthetics can be found in the study by Hassenzahl et al. [6], who asked users to compare six different designs of a process control application, with questionnaire inventories for experience, hedonic and appeal qualities. Hassenzahl et al. concluded that both experience and hedonic qualities contributed approximately equally to the overall judgement of appeal. However, these studies either did not specify which design features they varied to test aesthetic quality or varied on simple aspects such as colour and layout consistency as in Tractinsky's studies.

To our knowledge, no comparative studies have been undertaken on how interaction might influence aesthetics or user judgement of their "experience". One design feature which may attract users' attention, animated banner adverts, has been extensively researched. Bayles [1] found that animation in banner adverts was not effective in promoting memorability, while Guan and Zhang [4] and Diaper and Waeland [3] reported that although attention was directed towards animated adverts in terms of eye-tracking fixations, users did not comprehend or remember the information. Hornof and Halverson [7] have demonstrated that even fixations on animated adverts are not reliable indicators of attention, let alone comprehension of content. However, other factors which might contribute to the users' overall satisfaction, such as interaction and aesthetics have received less attention. 
This paper reports an evaluation of two websites with different design styles, one traditional, the other with interactive metaphors and more aesthetic design features. The study also investigates the link between design, usability, user perception and memory. In the following section we describe the experimental methods and materials. Section 3 reports the results of the usability, aesthetics heuristics and memory tests. The discussion then reviews the implications of the results for website evaluation and design.

\section{Method}

Two live websites were selected from the ThinkQuest Library, a collection of educational sites entered in an international competition sponsored by the Oracle Education Foundation. These websites presented the same content on Astronomy with very different design styles, one exploiting animated metaphors and more aesthetic features (metaphor-based), the other a traditional menu-based style. Example screenshots are shown in Fig. 1.

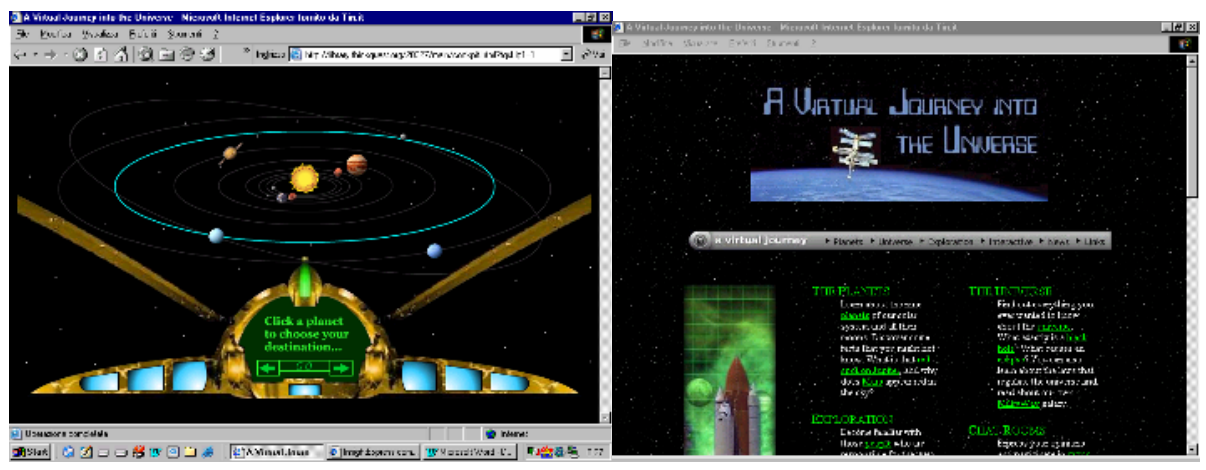

(a)

(b)

Fig. 1. (a) Metaphor-style interface showing the planets and cockpit metaphors, and (b) Menubased user interface

The sites had 210 content pages organised in four main sections - planets, universe, exploration, news, resources and glossary with further pages linking to mainly disabled interactive features such as chat rooms and feedback forms. From the home page (http://library.thinkquest.org/28327/), the user can select which style she/he prefers. In the interactive metaphor version, an animated representation of the solar system is displayed with a "cockpit" metaphor of controls at the bottom of the screen (see Fig. 1a). Moving the mouse over the planets causes an orbit to highlight, then clicking on the planet or its orbit causes the planet's name to appear in the cockpit display. Information about the planet can then be accessed by "Go" in the cockpit metaphor. Some fast moving planets such as Mercury were difficult to access, while Uranus and Neptune were not easily visible. The side panels in the cockpit 
contain other navigation links to chat rooms, universe, exploration, etc., although the user has to mouse over the panel to display the option name. The menu interface style, in contrast, (Fig. 1b) has a standard link menu structure to access information without any intervening displays. The top-level menu leads to sub-menus for the planets, and each planet has an introductory text followed by a sub-menu of information relevant to that planet. The key differences between the two interface styles which we hypothesised should influence user perception of engagement and aesthetics are summarised in Table 1.

Table 1. Informal assessment of the aesthetic/user engagement differences between the two interface styles

\begin{tabular}{lll}
\hline & Menu-based style & Metaphor-based style \\
\hline Interaction & Menu and links & $\begin{array}{l}\text { Interactive planets and cockpit } \\
\text { metaphors }\end{array}$ \\
Use of colour & $\begin{array}{l}\text { Black background, green and } \\
\text { white text } \\
\text { Layout \& presentation }\end{array}$ & $\begin{array}{l}\text { Conventional block structures } \\
\text { layout } \\
\text { white }\end{array}$ \\
Use of media & Text plus still image and shading emphasised \\
Background image & Starfield display borders & $\begin{array}{l}\text { Animation in several places, } \\
\text { interactive captions on images } \\
\text { Starfield display background }\end{array}$ \\
\hline
\end{tabular}

Table 2. Instruments and techniques used during the evaluation

\begin{tabular}{l|ll}
\hline Usability & $\begin{array}{l}\text { Self-report and severity rating of usability problems (1 minor } \\
\text { problem; 5 major problem) }\end{array}$ \\
Memorabilty & $\begin{array}{l}\text { - } 5 \text {-item usability scale on a 7-point Likert scale [9] } \\
\text { - Free recall memory test and attitude rating on 5 point scale (5 very } \\
\text { negative, } 1 \text { very positive) }\end{array}$ \\
Aesthetics & $\begin{array}{l}\text { - Heuristics for attractiveness [15], [16]) } \\
\text { Service quality }\end{array}$ & $\begin{array}{l}\text { - } 10 \text {-item perceived website aesthetic scale on a 7-point Likert scale [9] } \\
\text { Engagement }\end{array}$ \\
Willingness to use & -3 items measuring service quality on a 7-point scale [9] \\
\hline
\end{tabular}

To summarise the informal assessment, the two interfaces had minor differences in the layout, presentation, and graphics/font aspects of aesthetics; both used the same fonts and colour scheme, although the metaphor site used more interesting graphical and shading on titles and layout frames for the information. The clear differences lay in the interactivity, such as the solar system metaphor for accessing information, and information presentation with animation and pop-up captions on images. There was a slight difference in the use of background image to frame displays, with the metaphor site using the starfield space image more extensively. 
The websites were evaluated for usability, memorability of content and interface features, aesthetics, service quality, entertainment and willingness to use. A list of the techniques and instruments used in the study is reported in Table 2; details of the experimental procedure are reported in the following sections.

\subsection{Subjects}

Twenty-five undergraduate and postgraduate students (21 male and 4 female) from the School of Informatics, University of Manchester participated in the experiment. They all had basic knowledge of HCI, usability evaluation techniques and the aesthetic heuristics used in the experiment from the Multimedia and Virtual Reality course they had recently attended.

\subsection{Procedure}

Data were collected in a group setting, with each participant working individually for almost three hours. On arriving for the experimental session, the subjects received verbal and written instructions followed by a brief pre-test questionnaire recording personal data, Internet experience, and level of interest and knowledge of Astronomy. Then each subject was randomly assigned to one of the two websites and had to perform six information-retrieval tasks (e.g. what is the orbital period of Jupiter, what is the percentage of hydrogen in the composition of Jupiter) reporting their answers on a task sheet. Optimal task performance required visiting 17 pages in the menubased condition and 14 pages in the metaphor condition, the difference being pop up menus in the cockpit metaphor which allowed a shorter path.

While performing the tasks, subjects were invited to describe the usability errors they encountered and rate their severity. Once they had completed the tasks, subjects completed a free recall memory test. This required listing the first ten facts/items/issues they could remember about the website, and rating the quality of these memories on a five point scale as favourable, neutral or adverse. Then, they briefly revisited the site and completed the attractiveness heuristics and a questionnaire combining the remaining measures listed in Table 1. After a short break, the procedure was repeated with the other website and a new set of equivalent tasks which varied the planet chosen as subject (Jupiter, Uranus/Saturn, Neptune). Finally, a group discussion was run to investigate overall preferences and reasons behind them.

Interaction style was manipulated within-subjects, so that each participant evaluated both the menu-based and the metaphor-based interfaces. Evaluation order and tasks were counterbalanced among subjects and conditions.

\section{Results}

All scales and measures showed high reliability (Cronbach alpha $>.78$ ), thus comparative analyses were based on scale averages. Unless otherwise specified, intersite differences were tested by paired samples t-test. 


\subsection{Task Performance}

None of the subjects had any prior knowledge of the websites, and the overall knowledge and interest in the topic matter was moderately low. Nevertheless, information-retrieval performance was extremely accurate, with only $6 \%$ of 300 tasks resulting in inaccurate or wrong information. No difference between experimental conditions emerged.

\subsection{Usability}

Overall the usability evaluation favoured the menu-based website. On average, subjects reported significantly more problems when evaluating the metaphor-based site $($ mean $/$ subject $=4.2)$ than the menu-based design $($ mean $/$ subject $=2.32) t_{(24)}=-$ $3.41, p<.01$. The problems associated with the metaphor-based style were also judged to be more severe $($ mean $=3.65)$ than those associated with the menu-based style $($ mean $=3.02), t(160)=3.10, p<.01$. Usability problems were clustered in five general categories according to their cause, as illustrated in Table 3.

Table 3. Percentage frequencies of usability problems and average severity rating on a 1 to 5 scale ( 5 worst) classified by cause

\begin{tabular}{l|cccccc}
\hline & \multicolumn{3}{|c}{ Menu-based } & \multicolumn{3}{c}{ Metaphor-based } \\
\hline & Freq & $\%$ & Severity & Freq & $\%$ & Severity \\
\hline Poor menu/navigation & 25 & 43 & 2.80 & 71 & 68 & 3.54 \\
Poor graphical design & 16 & 27 & 2.60 & 18 & 17 & 3.17 \\
Poor information & 8 & 14 & 3.00 & 9 & 8 & 3.44 \\
Unexpected effect & 5 & 9 & 4.20 & 4 & 4 & 4.50 \\
Other & 4 & 7 & 2.50 & 3 & 3 & 3.67 \\
\hline Total & $\mathbf{5 8}$ & $\mathbf{1 0 0}$ & $\mathbf{3 . 0 2}$ & $\mathbf{1 0 5}$ & $\mathbf{1 0 0}$ & $\mathbf{3 . 6 5}$ \\
\hline
\end{tabular}

As can be seen from Table 3, problem frequency is significantly affected by interaction style $\left(\chi_{(2)}^{2}=6.62, p<.05\right)$ and the metaphor style encountered twice as many problems. Poor menu/navigation were usability problems which caused operational difficulties, i.e. critical incidents [11], whereas poor graphical design reflected adverse comments on aesthetic aspects and the subjects' design preferences, and poor information covered adverse comments on the clarity and completeness of the information architecture and content. Unexpected effect refers to unpredictable system behaviour that interrupted the user's task flow (e.g. unexpected pop-up window) or functionality failures.

When evaluating the metaphor-based interface, it was found that subjects reported $25 \%$ more poor menu/navigation problems than with the menu-based interface. However, with evaluation of the menu-based interface, subjects were $10 \%$ more likely to complain about graphical design than with the metaphor-based interface. It is worth noting that this distribution difference is not responsible for the difference in severity rating between the two styles. Indeed, an Anova on individual errors with style (2) and error category (3) as between-subjects factors indicated a significant effect for style, but neither for category nor for the interaction $(\mathrm{F}<1)$. The metaphor-based 
style was consistently evaluated more seriously in every problem category than the menu-based style; see the average severity scores in Table 3.

In the menu-based style, the most frequent problems in the poor menu/navigation category were the need for scrolling ( $\mathrm{N}=6$ events) and inconsistent use of the back and home button (7). In poor graphical design, the most common complaints were the unpleasant colour combination of green on black (6) and inconsistent use of text fonts (8). In this style most problem reports related to overall dissatisfaction with the design, and less frequently content, rather than problems with particular design features, apart from links (7).

In the metaphor-based style the more common problems were the lack of a caption for the planet name in the solar system metaphor $(\mathrm{N}=14)$; the difficulty of selecting a planet (double click procedure) (10) and the obscure interaction in the cockpit menu (8). The most troublesome design features were the solar system and planets metaphor, which was responsible $22 \%$ of the total errors, followed by the cockpit metaphor with $7 \%$. In contrast to the menu style, usability problems were frequently associated with specific design features.

The trend emerging from the objective usability analysis is reflected in the subjective evaluation. As shown in Fig. 2, subjects in the metaphor-based condition evaluated the usability of the site as significantly worse than in the menu-based design, $t(23)=3.02, p<.01$.

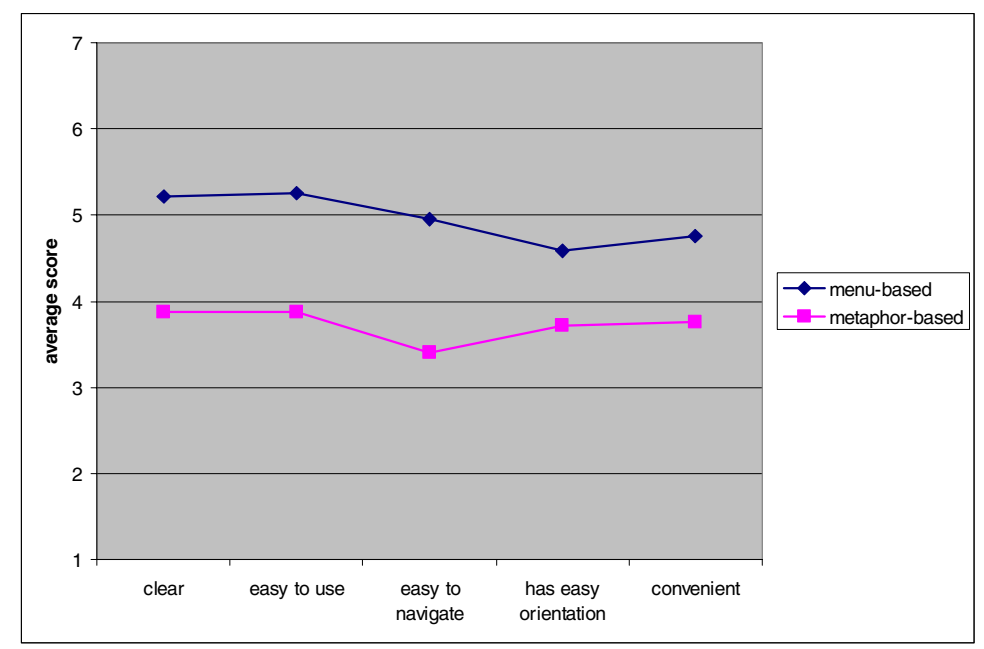

Fig. 2. Ratings in a post-test questionnaire on usability as a function of interaction style

\subsection{Aesthetics}

Following the factorial configuration proposed and validated by Lavie and Tractinsky [9], two dimensions were used: classical and expressive aesthetic. The classical aesthetics dimension included questions on pleasant, clear, clean, symmetric and aesthetic design; while expressive aesthetic dimension consisted of creative, 


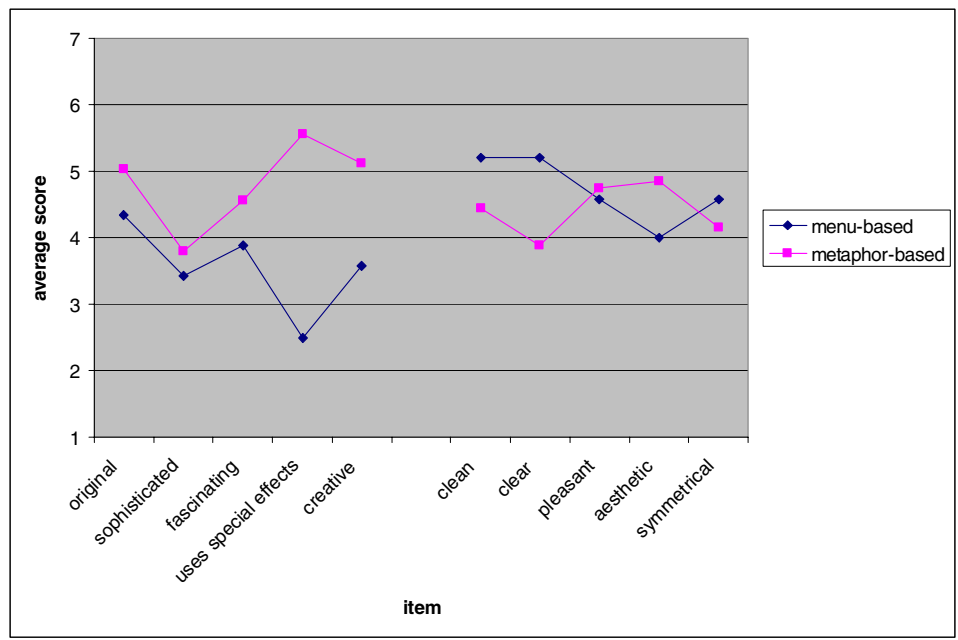

Fig. 3. Average scores on aesthetic evaluation factors as a function of interaction style

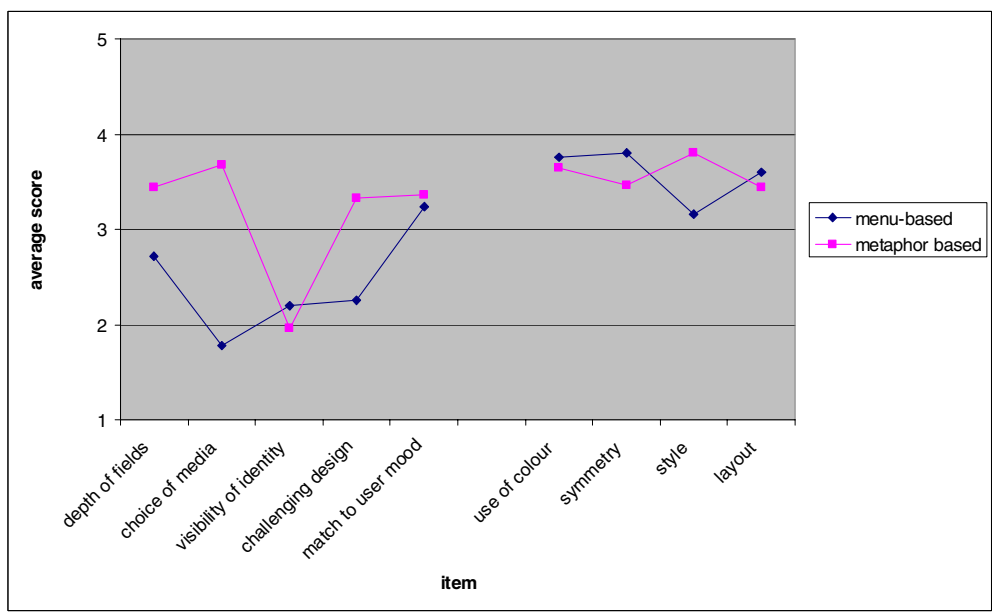

Fig. 4. Average scores on the expressive and classic clusters of the attractiveness heuristics

fascinating, original and sophisticated design with use of special effects. These two factors were then entered as dependent variables in a repeated-measure Anova with aesthetic dimension (2) and interaction style (2) as within-subjects factors. Both the main effects and their interaction were significant, namely aesthetic dimension: $F(1$, $22)=8.06, p<.01$; interaction style: $F(1,22)=4.75, p<.05 ; 2$-way interaction $F(1$, 22) $=30.01, p<.001$.

The effect of the interaction style on aesthetics is modulated by the dimension considered. There were no inter-site differences on the classical aesthetic dimension, 
but the menu-based style scored significantly lower on the expressive dimension. Average scores for individual items of the two aesthetic factors are shown in Fig. 3.

This result was confirmed by the analysis of the subjects' rating using the attractiveness heuristics which have been validated in previous studies [15], [16]. These refer more directly to design features which should promote aesthetic reactions than Lavie and Tractinsky's dimensions. The ten heuristics were grouped in two sets, reflecting classical and expressive dimensions, as illustrated in Fig. 4. Given the small size of our sample, we could not statistically confirm this configuration.

However, satisfactory Cronbach alpha and significant correlations $(p<.01)$ with the corresponding factors extracted from the questionnaire appealed to both internal and external validity. Results of the Anova on the heuristics showed significant differences between the interface styles on the aesthetic dimension $F(1,20)=16.34, p$ $<.01$; interaction style $F(1,20)=6.56, p<.05$; and a 2 -way interaction $F(1,20)=$ $20.62, p<.001$. Once again, there was no inter-site difference on the classical aesthetic dimension, while the expressive dimension scored higher in the metaphorbased interaction style.

\subsection{Service Quality and Engagement}

Interaction style significantly affected the perception of website quality, $t(23)=2.57$, $p<.05$, the menu-based website being perceived as more reliable and less error prone than the metaphor-based site. Conversely, the subjects' assessment of engagement tended to favour the metaphor-based site, $t(23)=-2.7, p<.05$, which was perceived as significantly more entertaining, engaging and enjoyable.

\subsection{Memory}

Overall, subjects reported 289 items in free recall memory of the two websites. No effect of interaction style emerged on the number of memory items retrieved or the memory valency in the different memory categories. However, a content analysis of these memories suggested that interaction style affected the content of retrieved items. Recalled items were categorised into reports relating to the user interface, sub-divided into visual design, use of colour, use of multimedia, comments on links and navigation features, labelling and feedback, and content memory, including reference to the subject matter and information architecture (see Fig. 6).

The menu-based style triggered more memories related to site content (56\% versus $44 \%$ in the metaphor-based condition). Conversely, the metaphor-based style invoked more memory related to UI elements and features, in particular multimedia elements ( $24 \%$ total items) and feedback mechanism (see Table 4). Memory valency, which we interpret as attitude, towards the more aesthetically related aspects of the design (graphics, use of colour and multimedia) were worse in the menu style, in contrast the metaphor style invoked adverse memory for interactive features such as navigation and feedback. The difference in subject attitude to information content between the two styles is strange since the content was the same; however, its presentation was more adventurous in the metaphor style with interactive titles and captions, so we conjecture this may have had a positive influence on the subjects' attitude. In the metaphor style the most frequently remembered features were the solar system/ 
planets metaphor (14 reports, average valency 2.71) followed by the cockpit (12 reports, average valency 3.61) so it appears that even though both these features caused high frequencies of usability problems, the solar system metaphor resulted in memory with a slightly negative attitude, whereas the cockpit metaphor provoked a more adverse reaction. No particular design features were remembered noticeably more than others in the menu condition, where memories related more to content.

Table 4. Frequencies and valency of items in free recall memory by category

\begin{tabular}{ll|cccccc}
\hline & & \multicolumn{3}{|c}{ Menu-based } & \multicolumn{3}{c}{ Metaphor-based } \\
\hline \multirow{2}{*}{ Content } & Freq & $\begin{array}{c}\text { Valen } \\
\text { cy }\end{array}$ & $\begin{array}{c}\text { Std. } \\
\text { error }\end{array}$ & Freq & $\begin{array}{c}\text { Valen } \\
\text { cy }\end{array}$ & $\begin{array}{c}\text { Std. } \\
\text { error }\end{array}$ \\
\hline \multirow{4}{*}{ UI } & Subject-matter & 37 & 2.57 & .18 & 32 & 2.60 & .24 \\
& Info architecture & 23 & 2.23 & .25 & 14 & 1.93 & .29 \\
\cline { 2 - 8 } & Graphical design & 16 & 3.13 & .35 & 15 & 2.33 & .40 \\
& Use of colour & 18 & 2.71 & .29 & 6 & 2.67 & .61 \\
& Multimedia & 12 & 2.92 & .42 & 35 & 2.91 & .24 \\
& Link and navigation & 29 & 2.74 & .30 & 34 & 3.22 & .22 \\
& Labelling/feedback & 2 & 2 & 0 & 12 & 3.92 & .31 \\
& Other & 1 & 1 & 0 & 3 & 4 & .58 \\
\hline & Total & $\mathbf{1 3 8}$ & $\mathbf{2 . 4 1}$ & $\mathbf{0 . 2 2}$ & $\mathbf{1 5 1}$ & $\mathbf{2 . 9 5}$ & 0.36 \\
\hline
\end{tabular}

A total of 138 memory items were explicitly related to the aesthetic dimensions, namely information quality, usability, expressive aesthetic and classical aesthetic. For the menu-based interface subjects tended to retrieve memory related to information quality $(31 \%)$, classical aesthetic (30\%), usability issues $(25 \%)$ and finally expressive aesthetic (14\%); in contrast, the most common items for the metaphor-based interface related to usability (36\%), followed by expressive aesthetic (30\%), information quality (21\%) and classical aesthetics (13\%). The quality of these memories was not significantly different, with the clear exception of usability, which generated more negative memories in the metaphor-based condition than in the menu-based one $(t(61)=-2.66, p<.01)$.

\subsection{Group Discussion}

During the group discussion, all subjects agreed that the metaphor-based website was worse for usability and many subjects pointed out problems with using the design. Nevertheless, when asked which of the two sites they personally preferred and might be willing to use again in the future, all but one subject voted for the metaphor-based style. Their preference was explicitly driven by an increase in engagement and pleasure experienced during the interaction, even though this came at the cost of increased initial workload to understand interaction procedures. It is worth noting that subjects were mostly attracted by the planet animation on the front page which strongly appealed to their curiosity even though it was clearly recognised as the worst usability feature of the design. However, when asked to assess which of the two sites was more suitable for teaching secondary school pupils, the subjects were evenly divided between the two interaction styles. The main reasons cited in favour of the 
menu-based style were simplicity and clarity; while the reasons in favour of the metaphor-based style were engagement by interaction and motivation.

\subsection{Summary}

The matrix reporting correlations between the main dimensions under investigation is reported in Table 5. Correlation values are reported separately for the two style conditions. Metaphor style values are in the upper part of the table; menu values are in the lower part of the table. Note that as the high correlations between aesthetic dimensions assessed by questionnaires and heuristics have already been discussed in section 3.3, in the table we report only questionnaire values, for consistency with the other measures.

Table 5. Correlation matrix of the study's measures. * $=\mathrm{p}<.05 ; * * \mathrm{p}<.01 ; * * * \mathrm{p}<.001$

\begin{tabular}{l|l|cccccc}
\hline & & \multicolumn{5}{|c}{ Metaphor measure combination. } \\
\cline { 2 - 8 } & & 1. & 2. & 3. & 4. & 5. & 6. \\
\hline \multirow{2}{*}{$\begin{array}{l}\text { Menu } \\
\text { measure }\end{array}$} & 1. Memory valency & & $*$ & $* *$ & & & $*$ \\
combin- & 2. Usability & $* *$ & & $* *$ & $*$ & $* *$ & $* *$ \\
ation & 3. Classical_A & & $* *$ & & $* *$ & $* *$ & $* *$ \\
& 4. Expressive_A & & $* *$ & $* *$ & & $*$ & $*$ \\
& 5. UI_quality & & $* *$ & $* *$ & & & $*$ \\
\hline
\end{tabular}

Table 6. Summary of the differences between the two interactive styles, + denotes better style for the dimension, - worse style, = no difference between the styles

\begin{tabular}{lcc}
\hline Dimensions & Metaphor-based style & Menu-based style \\
\hline Usability & - & + \\
Aesthetic classic & $=$ & $=$ \\
Aesthetic expressive & + & - \\
Information quality & - & + \\
Engagement & + & - \\
Memory & Content-based & Interface-based \\
\hline
\end{tabular}

The overall correlation trend demonstrates the inter-relationships between the different evaluation dimensions. The most striking difference between the two styles regards memory valency, which in the menu-based condition correlates only with usability; whereas the metaphor-based condition correlates also with classical aesthetic and engagement. A summary of the results of the different evaluation dimensions assessed is given in Table 6. 
The menu style was superior for usability and perceived to have better information quality, even though both sites had exactly the same content. Both sites were rated positively for classic aesthetics in both the attractiveness heuristics and Tractinsky's dimension. However, the metaphor style was superior for the expressive aesthetics on both measures and was preferred overall. This preference was partially reflected in the subjects' memory which was slightly more positive for the metaphor site, but it appears that the subjects' judgement of overall quality differed from their attitude to specific design features and recall of separate aspects of each site. In conclusion, aesthetics does appear to have an important effect, since the subjects preferred the site they rated as being better designed aesthetically even though they were aware of its poor usability.

\section{Discussion}

Advocates of the new usability [5] argue that aesthetics should be an important determinant of users' satisfaction with a design; however, there have been remarkably few experimental studies to determine which design features may aesthetically enhance users' experience. We have demonstrated that interactive metaphors do contribute strongly to users' attitude and rating of website design even though the users' usability experience was worse with the more aesthetic design style. Furthermore animation and interaction may have had a positive effect on user perception of content which is an important finding for education related web sites.

The attractiveness heuristics [15], [16] we proposed assess design features which should contribute towards positive aesthetic expression, unlike previous evaluation instruments which have assessed users' judgement of qualities that can be clustered under the umbrella of aesthetics perception [9]. The aesthetics heuristics we describe correspond most closely to the expressive aesthetics dimension which Lavie and Tractinsky [9] found in a factor analysis of evaluation questions; however, their questions focused on users' perception of user interface qualities, such as "beautiful", "challenging", "fascinating", whereas our questions are judgements on the quality and use of more specific design features and media. The correlation of the aesthetic heuristics and dimensions suggests that the attractiveness heuristics may be reasonable indicators of design qualities for expressive aesthetics, although we can not exclude other factors, such as user reaction to the specific metaphor, which may influence individuals' judgement.

Tractinsky [17] demonstrated that users' perception of aesthetic qualities was an important, and culturally variable, component in the rating of quality and experience in experiments in ATM user interfaces. However, the study varied only low-level graphical design (e.g. colour button format) and visual layout features, whereas we have demonstrated that interaction and metaphors also have a powerful effect not only on user perception of aesthetics but also on their judgement of satisfaction and engagement. The questionnaire assessment study by Hassenzahl et al. [6] does not detail the changes they made to the six design variations used in their study so it is difficult to assess the causal factors influencing user perception. 
The strong effect of interaction on aesthetic judgement and satisfaction which we found can be explained by affective interpretations of user judgement [14], in that the metaphors invoke user curiosity and pleasure even if they are clearly more difficult to use. Our study provides some evidence that aesthetic design and interactive metaphors do form an important influence on users' overall judgement of their experience, which overrides a poor usability experience. However, users may not forget such poor experiences since their memory for problematic features was adverse; furthermore, they make different judgements about the interfaces for scenarios of serious educational use. Further investigations need to be carried out to assess the impact of different metaphors and design qualities on user perceptions of engagement, and to assess the relative contributions of "static" aesthetics (e.g. layout, colour, graphics), use of media and interactive effects.

\section{References}

1. Bayles, M. Designing online banner advertisements: Should we animate? CHI Letters, 4(1), (2002) 363-366.

2. Beier, B., \& Vaughan, M. W. The bull's-eye: A framework for web application user interface design guidelines. In V. Bellotti, T. Erickson, G. Cockton, \& P. Korhonen, (Eds). CHI 2003 Conference Proceedings: Conference on Human Factors in Computing Systems, Fort Lauderdale FL 5-10 April 2003. New York: ACM Press, (2003), 489-496.

3. Diaper, D., \& Waelend, P. World Wide Web working whilst ignoring graphics: Good news for web page designers. Interacting with Computers, 13(2), (2000) 163-181.

4. Guan, S. U., \& Zhang, X. The design and implementation of a web-based personal digital library. Journal of the Institution of Engineers, 44(3), (2004) 59-77.

5. Hallnas, L., \& Redstrom, J. From use to presence: On the expression of aesthetics of everyday computational things. ACM Transactions on Computer-Human Interaction, 9(2), (2002) 106-124.

6. Hassenzahl, M., Platz, A., Burmester, M., \& Lehner, K. Hedonic and ergonomic quality aspects determine a software's appeal. In T. Turner, G. Szwillus, M. Czerwinski, \& F. Paterno, (Eds). CHI 2000 Conference Proceedings: Conference on Human Factors in Computing Systems, The Hague 1-6 April 2000. New York: ACM Press, (2000), 201-208.

7. Hornof, A., \& Halverson, T. Cognitive strategies and eye movements for searching hierarchical computer displays. In V. Bellotti, T. Erickson, G. Cockton, \& P. Korhonen, (Eds). CHI 2003 Conference Proceedings: Conference on Human Factors in Computing Systems, Fort Lauderdale FL 5-10 April 2003. New York: ACM Press, (2003). 249-256.

8. IBM. Ease of use: Design principles. http://www.ibm.com/ibm/easy/ eou_ext.nsf/Publish/6. (20 November 2000).

9. Lavie, T., \& Tractinsky, N. Assessing dimensions of perceived visual aesthetics of websites. International Journal of Human-Computer Studies, 60(3), (2004) 269-298.

10. Lynch, P. J., \& Horton, S. Web style guidelines (2nd ed.). New Haven CT: Yale University Press, (2001).

11. Monk, A., Wright, P., Haber, J., \& Davenport, L. Improving your human-computer interface: A practical technique. London: Prentice Hall, (1993).

12. Nielsen, J. Designing web usability: The practice of simplicity. New Riders, (2000).

13. Nielsen, J. Usability engineering. New York: Academic Press, (1993).

14. Norman, D. A. Emotional design: Why we love (or hate) everyday things. New York: Basic Books, (2004). 
15. Sutcliffe, A. G. Assessing the reliability of heuristic evaluation for website attractiveness and usability. In Proceedings HICSS-35: Hawaii International Conference on System Science. Honolulu: University of Hawaii, (2002). 1838-1847.

16. Sutcliffe, A. G. Heuristic evaluation of website attractiveness and usability. In C. W. Johnson (Ed.), Proceedings: 8th Workshop on Design, Specification and Verification of Interactive Systems, Glasgow 13-15 June 2001. Berlin: Springer-Verlag, (2002). 188-199.

17. Tractinsky, N. Aesthetics and apparent usability: Empirically assessing cultural and methodological issues. In Pemberton S. (Ed.), Human Factors in Computing Systems: CHI 97 Conference Proceedings, Atlanta GA 22-27 May 1997. New York: ACM Press, (1997), 115-122. 